\title{
Influência geológica na dinâmica fluvial da bacia hidrográfica do córrego Cachoeirinha, Cáceres, Mato Grosso
}

O objetivo desse trabalho é mostrar a caracterização geológica e analisar sua inter-relação com a dinâmica fluvial do córrego Cachoeirinha. A bacia hidrográfica do córrego Cachoeirinha está localizada no sudoeste do Estado de Mato Grosso e a nordeste do município de Cáceres. Afluente da margem esquerda do rio Paraguai, sua área de abrangência é de 944,104 Km², cujas

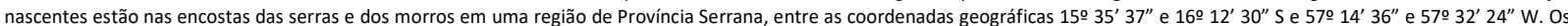
procedimentos metodológicos iniciaram-se com trabalhos de gabinete e posterior pesquisa de campo. Por apresentar diferentes características físicas, a área da bacia foi dividida em três setores: alto, médio e baixo curso, sendo delimitada através de quatro cartas topográficas do Ministério do Exército (1975) em escalas de 1:100.000, sendo: folhas de Cáceres, Três Rios, Serra setores: alto, médio e baixo curso, sendo delimitada através de quatro cartas topográficas do Ministério do Exército (1975) em escalas de 1:100.000, sendo: folhas de Cáceres, Três Rios, Serra mostraram que a bacia é embasada pelas formações: Sepotuba, Raizama e Araras no alto curso; Pantanal, Sepotuba, Araras e Raizama no médio curso, os Aluviões Atuais e a Formação Pantanal no baixo curso na qual interferem diretamente na dinâmica fluvial ao longo da bacia, sendo: na disponibilidade de nascentes, de canais fluviais, no padrão de escoamento e na morfologia do canal.

\section{Geological influence in the fluvial dynamics of the hydrographic Cachoeirinha stream, Cáceres, Mato Grosso}

\begin{abstract}
The purpose of this work is show the geological description and analyze your interrelationship with the river Cachoeirinha dynamics. The hydrographic basin of this river can be located in the southeast of the Mato Grosso State and the northeast of the Cáceres city. Tributary of the left bank of the Paraguay River. It covers $944,104 \mathrm{~km}$, whose springs are in the slopes and hillsides

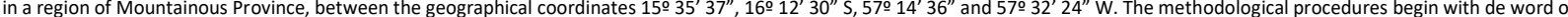
cabinets and subsequent field research. For show different physical characteristics the area of the basin was divided into three sectors: high, medium and low course, being delimited between four Sepotuba, Razama and Aras on the rightcourse; Pantana which it interferes directly in river dynamics on the long of basin, so: on availability of sources, of rivers channels, on the flow pattern, and on channel morphology.
\end{abstract}

Keywords: Description; Geologic; River Dynamics.

Topic: Geomorfologia

Reviewed anonymously in the process of blind peer.
Received: 02/02/2018

Approved: 20/05/2018
Marcos dos Santos (iD)

Universidade do Estado de Mato Grosso, Brasil

http://lattes.cnpq.br/2037930811007128

http://orcid.org/0000-0002-7014-4988

mdsantos_23@hotmail.com

Celia Alves de Souza (iD

Universidade do Estado do Mato Grosso, Brasil

http://lattes.cnpq.br/4260661798494235

http://orcid.org/0000-0002-9068-9328

celiaalvesgeo@globo.com
Referencing this:

SANTOS, M.; SOUZA, C. A.. Influência geológica na dinâmica fluvial da bacia hidrográfica do córrego Cachoeirinha, Cáceres, Mato Grosso. Revista Ibero-Americana de Ciências Ambientais, v.9, n.1, p.197-207, 2018. DOI: http://doi.org/10.6008/CBPC2179-6858.2018.001.0014 


\section{INTRODUÇÃO}

Os fundamentos teóricos desta pesquisa referentes a definição de bacia hidrográfica pautam-se em estudos realizados pelos pesquisadores Leopold (1971), Silveira (1993), Christofoletti (1999), Brigante e Espíndola (2003), Valente e Gomes (2005), Guerra e Guerra (2008) e Botelho (2010), cujos autores defendem que é um conjunto de terras drenadas por um rio e seus afluentes em uma determinada área da superfície terrestre. Os limites são delimitados pelo divisor de águas com maior altitude, criados pelo próprio escoamento ao longo do tempo, tendo como fatores reguladores o volume do fluxo de entrada e de saída de água, a topografia, a vegetação, o material de origem e o clima.

Cunha (2008) e Cunha e Guerra (2009) salientam que a bacia hidrográfica é uma unidade geomorfológica de extrema importância, por interagir com o conjunto de elementos naturais e antrópicos. Ross (2009) diz que os elementos que compõem as características ambientais de uma determinada bacia hidrográfica não são isolados. O relevo é apenas um de seus integrantes e está relacionado com as rochas que o sustenta, com o clima que o esculpe e com os solos que o recobre. Através de uma ação simultânea, embora de forma desigual, ao longo do tempo e do espaço todos se modificam continuamente, influenciando e sendo influenciados. Desse modo, através de estudos ambientais, os resultados servem de indicadores às potencialidades dos recursos naturais e, ao mesmo tempo, às fragilidades locais.

Segundo Suguio e Bigarella (1990), os elementos físicos ambientais: climático, recobrimento florestal, bem como, a capacidade de infiltração (solo), influência geológica e geomorfológica influenciam diretamente no condicionamento do escoamento superficial (deflúvio) em uma bacia hidrográfica, indicando a quantidade total das águas das precipitações que alcançam o canal fluvial.

Tratando-se de pesquisas que realizaram a caracterização ambiental de bacias hidrográficas, existem várias podem ser evidenciadas, tais como: Ross (1987), com "o estudo e a cartografia geomorfológica da Província Serrana de Mato Grosso"; Souza (1998), trabalhando na "bacia hidrográfica do córrego Piraputanga-MT"; Ritela e Souza (2008), com "a caracterização da bacia hidrográfica do rio Aguapeí-MT"; Soares (2009), com o "estudo de nascentes: subsídio a políticas de gestão da sub-bacia hidrográfica do córrego Caeté no sudoeste do Estado de Mato Grosso"; Souza e Tosta (2010) na "sub-bacia do córrego Macaúba/MS" e Andrade et al. (2012) estudando "os processos deposicionais na foz da baía Salobra com o rio Paraguai, Cáceres-MT", entre outras.

Considerando a bacia em estudo como afluente da margem esquerda do rio Paraguai, torna-se imprescindível a realização desta pesquisa. Uma vez que, além da inter-relação das características ambientais na própria bacia que devem ser conservados, o fluxo do córrego Cachoeirinha transporta não só a água, mas também sedimentos das encostas, das áreas de uso agrícola e da própria calha para o rio Paraguai e consequentemente para o Pantanal.

Desse modo, este estudo objetivou realizar um levantamento das características ambientais geológicas e suas relações com a dinâmica fluvial da bacia hidrográfica do córrego Cachoeirinha, afluente da margem esquerda do rio Paraguai, localizada no sudoeste do Estado de Mato Grosso. 


\section{MATERIAL E MÉTODOS}

\section{Área de Estudo}

A bacia hidrográfica do córrego Cachoeirinha possui suas nascentes na Província Serrana, percorre a área de depressão do Alto Paraguai e deságua junto à planície de inundação da margem esquerda do rio Paraguai. Localiza-se no sudoeste do Estado de Mato Grosso e a nordeste do município de Cáceres, entre as

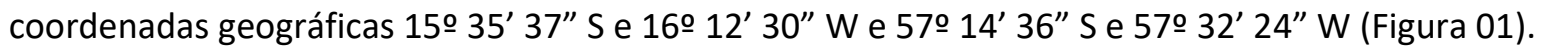

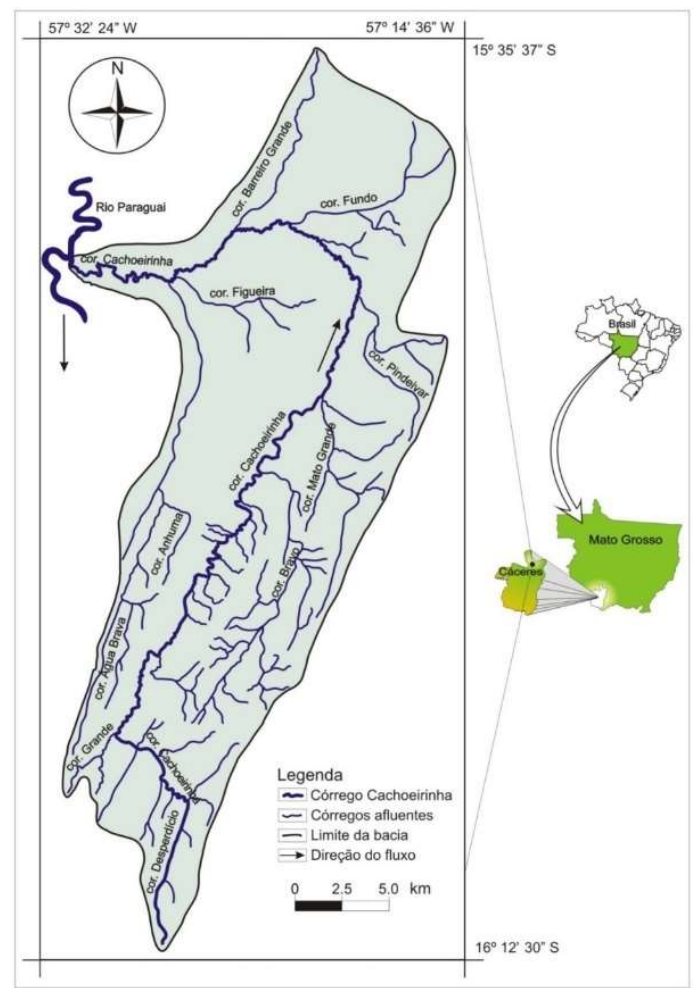

Figura 01 - Mapa de localização da bacia hidrográfica do córrego Cachoeirinha.

Elaborado pelo autor a partir dos dados das cartas topográficas do Ministério do Exército (1975).

\section{METODOLOGIA}

A bacia hidrográfica do córrego Cachoeirinha, por apresentar particularidades nas diferentes características ambientais, tais como: clima, geologia, solo, vegetação, especialmente na geomorfologia, que refletem diretamente no sistema hidrográfico como um todo, possibilitou ser divida em três setores: alto, médio e baixo curso.

\section{Caracterização Ambiental}

Para delimitar e evidenciar os cursos de água presentes na bacia foram utilizadas as cartas topográficas da Diretoria do Serviço Geográfico (DSG) do Ministério do Exército (1975) Folhas: SE. 21-V-B-II - CÁCERES, SD. 21-Y-D-V - TRÊS RIOS, SE. 21-V-B-III - SERRA DA CAMPINA e SD. 21-Y-D-VI - SERRA DA PALMEIRA na escala de 1:100.000. 
A caracterização dos elementos ambientais foi realizada por meio da compilação das informações presentes no Relatório do Projeto RADAMBRASIL (1982), bem como, do mapa temático de Geologia com escala de 1:1.000.000.

Para a elaboração dos mapas, foram digitalizadas as áreas de interesse que envolvia a bacia. Utilizando-se o programa CorelDRAW - Versão X3, foi realizado a vetorização delimitando o componente ambiental geologia, inserindo as respectivas cores e demais informações importantes que devem constar em um mapa. Após a atividade de gabinete foram realizadas visitas a campo para observação, caracterização e confirmação das informações compiladas nos livros, relatórios e mapas utilizados.

\section{RESULTADOS E DISCUSSÃO}

A área de estudo está inserida na Formação do Grupo Alto Paraguai, sendo composta por rochas que datam do Pré-Cambriano Superior até os sedimentos recentes do Quaternário. Após terem sido dobradas, aplanadas e inundadas por cobertura cretácica, as rochas foram posteriormente soerguidas através de processos epirogenéticos e a seguir passaram a ser exumadas e esculpidas por processos erosivos que se desenvolveram ao longo do Cenozóico. Esta atividade desenvolvida por agentes pluviofluviais, atuaram alternadamente em fases climáticas secas e úmidas, contribuindo com o rebaixamento do relevo onde as rochas se mostraram menos tenras e, preservadas nos locais de maior resistência, formando as superfícies mais altas (BARROS et al., 1982).

As litologias que datam do Pré-Cambriano Superior encontradas na bacia do córrego Cachoeirinha destacam-se das mais antigas para as mais recentes, ou seja: Formação Araras (calcários e dolomitos); Formação Raizama (arenitos ortoquartzíticos e feldspáticos) e Formação Sepotuba (folhelhos) composta por rochas sedimentares esculpidas em estruturas dobradas antigas, conforme é destacado na Figura 02.

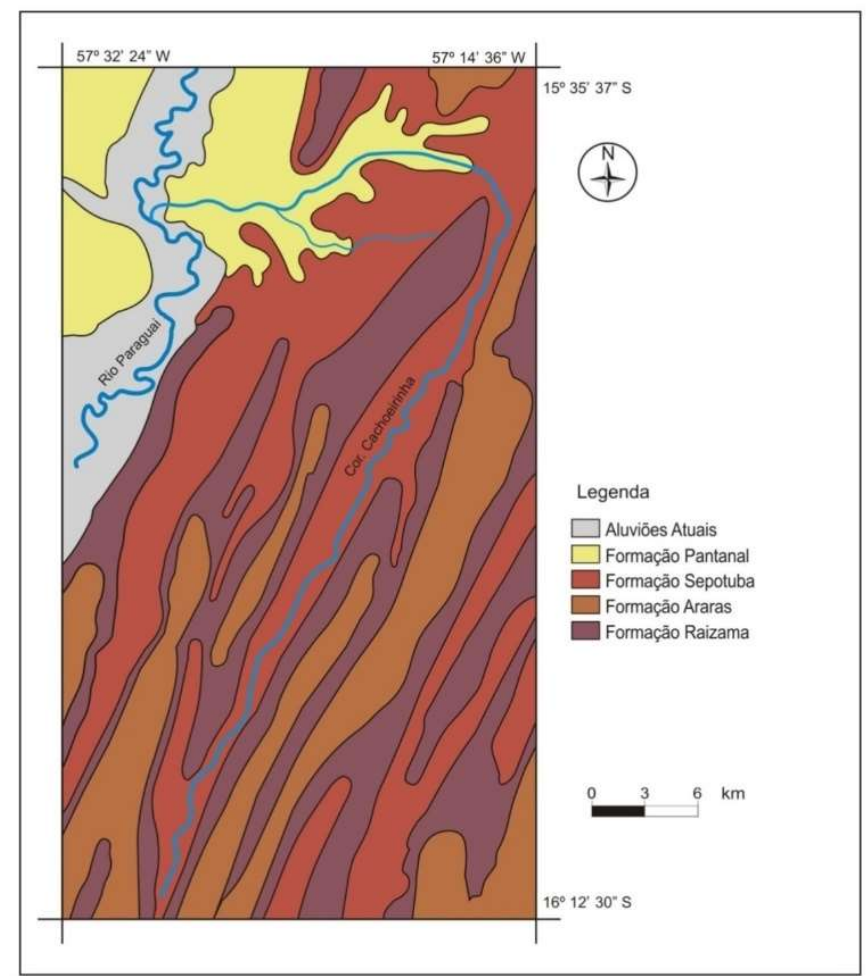

Figura 02 - Mapa Geológico da bacia hidrográfica do córrego Cachoeirinha. Fonte: RADAMBRASIL (1982). 
As estruturas geológicas quaternárias tiveram início a 1,6 milhões de anos e prolongam-se até os dias atuais, sendo explicadas por Suguio (2010) como a superposição das camadas de sedimentos. Marcada por grandes oscilações climáticas seco-úmida, as camadas sedimentares estão assentadas horizontalmente, na qual possuem um significado cronológico temporal. Possuíam a denominação de rochas primárias, secundárias e terciárias, que posteriormente, foram substituídas por Paleozóicas, Mesozóicas e Cenozóicas.

O alto curso da bacia hidrográfica do córrego Cachoeirinha comporta os seguintes embasamentos geológicos: Formação Raizama, Sepotuba e Araras.

\section{Formação Raizama}

Litologicamente a Formação Raizama apresenta em sua base frequentes intercalações de camadas de arenitos grosseiros e conglomerados com matriz arenosa fina, média e grossa. É constituído por cores claras, com tonalidades esbranquiçadas, bege, cinza-claro, rósea e mais raramente arroxeada, camadas conglomeráticas com seixos de quartzo atingindo até $3 \mathrm{~cm}$ (BARROS et al., 1982).

Uma das primeiras citações às rochas desta unidade litoestratigráfica foi a de Evans (1894), que as nomeou de Raizama Sandstone, por serem formadas por arenitos feldspáticos. Almeida (1964) menciona que, a origem da sedimentação do Arenito (Formação Raizama) ocorreu em águas pouco profundas, epineríticas, e que tal bacia sofria lentamente as consequências das mudanças climáticas, mas ainda contínua em subsidência na Província Serrana, comprovada pela espessura da sua formação.

Em termos morfológicos, de acordo com Oliveira e Leonardos (1943), a composição dos morros e das serras do alto curso da bacia é de Arenito da Formação Raizama. Analisando as cartas topográficas do Projeto Radambrasil (1982), as formações de arenito registrados nas serras: Cachoeirinha, serra Branca, serra da Chapola, serra da Campina, serra da Santana, serra Grande, serra Morro Branco e serra Morro Grande, conforme os pacotes rochosos resistentes, mantêm a estrutura e alguns taludes verticais.

Para Karmann (2009), o arenito é uma unidade rochosa porosa, permeável que possui a capacidade de armazenar e de transmitir grandes quantidades de água para o lençol freático, sendo considerado de suma importância ao abastecimento dos aquíferos e à formação das nascentes. As evidências de que o Arenito influência no Afloramento do lençol freático nas fendas da rocha de arenito é mostrado na figura 03, localizada na encosta ocidental da serra da Chapola (alto curso) onde há uma das nascentes do córrego Cachoeirinha, associada ao afloramento de aquífero.

O padrão de escoamento do alto e médio curso do córrego Cachoeirinha percorre o fundo do vale de forma meandrante e encaixado, típico de locais que possuem o controle estrutural geológico. O perfil transversal entre as margens é em formato de " $U$ ", verificando-se a profundidade da calha que varia de 0,90 cm a 5,00 metros. O desnível nas encostas das serras compostas de arenito contribui para direcionar o escoamento pluvial convergindo para o canal fluvial. A água ao alcançar o leito não encontra áreas de escape ou de inundação, concentrando o fluxo na calha do córrego. 
Em função da declividade longitudinal do alto para o baixo curso do canal, torna o escoamento fluvial rápido e turbulento durante o período de cheia, acelerando o processo da erosão vertical (fundo), das margens e no transporte de sedimentos da montante para jusante, tais como: blocos e matacões de rocha e principalmente areias (Figura 04).

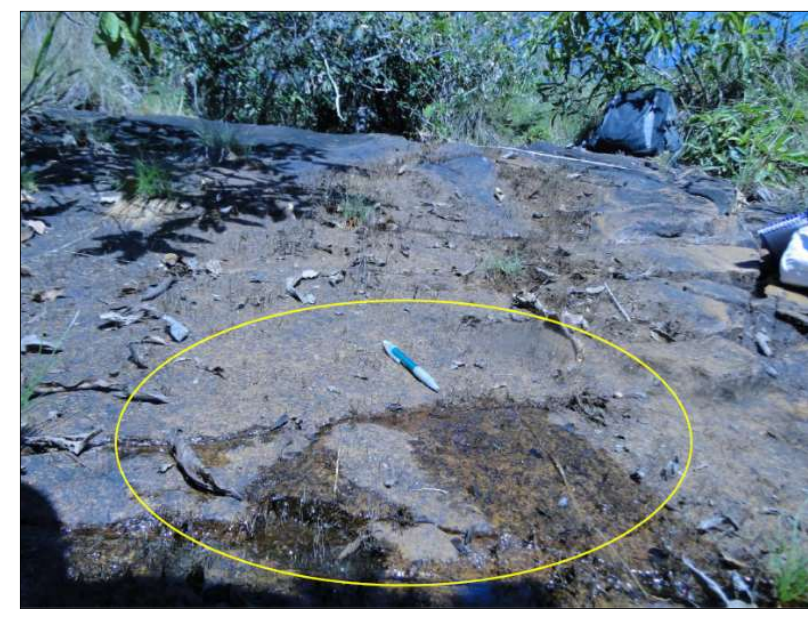

Figura 03: Afloramento do lençol freático nas fendas da rocha de arenito. Foto: Santos. Local: $16^{\circ} 11^{\prime} 57,9^{\prime \prime} \mathrm{S}$ e $57^{\circ} 27^{\prime} 30,1^{\prime \prime} W$.

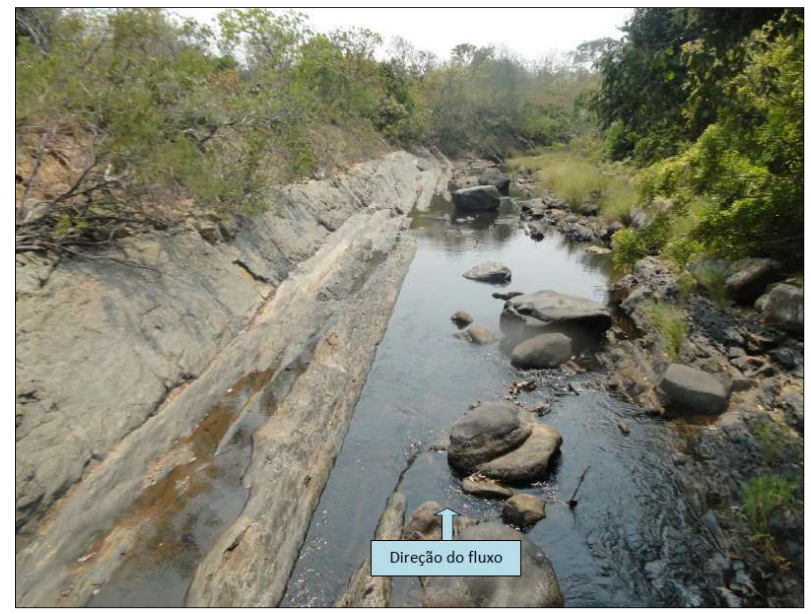

Figura 04: Aprofundamento do canal em rochas de arenito da formação Raizama. Foto: Santos. Local: $16^{\circ} 11^{\prime} 49^{\prime \prime}$ S e $57^{\circ} 27^{\prime} 31,53^{\prime \prime}$ W.

Para Nunes et al. (1994), nos canais que sofrem o controle estrutural, ocorre aprofundamento no canal, maior do que o desgaste marginal. Entende-se que o maior ataque da força do fluxo é no fundo do canal em razão do próprio volume líquido e do material grosseiro que é transportado.

Christofoletti (1980) corrobora dizendo que a erosão fluvial nos ambientes onde ocorre o controle estrutural e o encaixamento do canal fluvial pode incidir sob dois processos: corrasão e cavitação. Desse modo, no alto do córrego Cachoeirinha, a corrasão provocou o polimento das margens e do fundo do canal, devido a ação do atrito ou impacto das partículas em suspensão, carregadas pelos fluxos turbulentos da água durante os períodos de cheia. Pela cavitação, a água sob condições de velocidade elevada promoveu a fragmentação dos blocos de rocha em arenito, depositando-os dentro do leito. Além dos pequenos detritos, os pacotes rochosos e as formas topográficas do fundo do canal compõem a rugosidade do leito (figura 04).

Considerando o controle estrutural exercido pelos componentes geológicos (arenito) e geomorfológicos (serras e morros) da Província Serrana no alto e médio curso do córrego Cachoeirinha, faz com que o canal fluvial apresente trechos encaixados, pequenos segmentos retilíneos e outros com contínuos meandros. De acordo com Popp (2010), a presença do quartzo nas rochas areníticas, resistente e estável quimicamente pode tornar lento o processo de desgaste na calha fluvial, sendo um dos fatores que deve ser considerado na composição das formas dos canais fluviais.

\section{Formação Araras}

A estruturação da Formação Araras no estado de Mato Grosso é constituída por rochas carbonáticas, sendo caracterizada na porção inferior e meias encostas, essencialmente por calcários pelíticos e calcíticos. 
O calcário dolomítico ocorre com maior abundância, apresentando feições topográficas típicas desta formação, constituindo colinas e morros abaulados no topo, alinhados e alongados no sentido da estrutura regional (BARROS et al., 1982). Na bacia hidrográfica do córrego Cachoeirinha registra-se a ocorrência dessa Formação na serra das Araras, Lavandeira, Jigum, Morraria, Monjolinho, Muquem e Cachoeira.

Luz et al. (1978) e Wilson (1975) fizeram um estudo mais específico e detalhado das rochas da Formação Araras, envolvendo o levantamento geológico e geoquímico, admitindo a espessura de 1.300 metros para esta unidade. Admite-se que o conjunto carbonático da Formação Araras depositou-se em ambiente marinho raso de águas calmas tipo plataforma. Segundo a sequência idealizada de fácies e com base nas características litológicas, acredita-se que as rochas calcárias da porção inferior do pacote estariam mais relacionadas às fácies de plataforma aberta, provavelmente sublitorânea e os dolomitos na plataforma restrita, aproximadamente litorânea.

Para Karmann (2009), a dissolução do calcário provoca a formação de fendas com maior propensão à ocorrência de drenagem subterrânea através de sumidouros, dutos e dolinas. Desse modo, A formação litológica influencia na disponibilidade da rede de drenagem na bacia hidrográfica do córrego Cachoeirinha, especificamente nas áreas de ocorrência do calcário, onde existe uma redução na densidade de drenagem superficial, estando associada à própria litologia, possibilitando que os lençóis aquáticos possam permanecer subterrâneos nos veios criados pela dissolução das rochas, sem aflorar na superfície.

\section{Formação Sepotuba}

De acordo com os mapas editados junto ao relatório do Projeto Radambrasil (1982), a Formação Sepotuba é composta de argilitos, folhelhos e siltitos, ocorrendo de forma mais intensa no alto curso e moderadamente em alguns locais do médio curso da bacia, ocupando os flancos mais externos das anticlinais e as estruturas dobradas em sinclinais onde está o curso do córrego Cachoeirinha. As sinclinais onde aparecem os folhelhos estão entre as serras da Chapola e a serra da Cachoeira, serra Morro Grande e serra Branca, serra da Cachoeirinha e a serra do Muquem e entre as serras das Araras e a serra do Jigum.

Barros et al. (1982) afirmam que, litologicamente, a Formação Sepotuba é caracterizada, em sua seção basal, por frequentes intercalações de siltitos finamente laminados, folhelhos e arenitos finos a médios, em cores vermelho-escuro, marrom-chocolate e cinza-esverdeado, todas provavelmente de origem primária. São caracterizados por espessos pacotes, os quais se apresentam em camadas finamente estratificadas, localizadas no fundo do vale escavado na encosta oriental da serra das Araras.

Conforme as observações realizadas nos trabalhos de campo, percebe-se que nos locais onde aparecem os afloramentos de Folhelhos, a erosão no fundo do canal está mais estável. Fato que é confirmado por Souza (1998) trabalhando com a bacia hidrográfica do córrego Piraputanga-MT, onde mostrou que o processo erosivo foi mais intenso nas margens compostas de arenito, calcário e principalmente nas formações recentes do Quaternário (Aluviões Atuais e Formação Pantanal), quando a erosão acumulada em um período de monitoramento de sete meses foi de 5 a $20 \mathrm{~cm}$, enquanto na formação Sepotuba ocorreu de 1 a $8 \mathrm{~cm}$. 
O leito do córrego Cachoeirinha, no segmento do alto e médio curso é bem encaixado, tanto nas margens, quanto no fundo do canal, onde está encoberto pela formação Sepotuba, assim continuará a resistir à ação erosiva das águas. Por outro lado, devido à baixa permeabilidade e o sistema de diaclasamento dos folhelhos, há evidências de significativa formação de novos canais nos fundos dos vales entre as serras e os morros, aumentando a densidade de canais e de drenagem nos locais onde são embasados por essa litologia.

De acordo com Almeida (1964), caracterizando a transição entre os Arenitos da Formação Raizama e os Folhelhos da Formação Sepotuba, concluiu-se que esses últimos pareciam corresponder ao complemento argiloso daqueles e acumulados em águas mais profundas, a maior distância da costa do mar transgressivo. Dentro desse raciocínio, parece mais provável que os folhelhos da Formação Sepotuba caracterizem um ambiente de mares transgressivos. São bem estratificadas, laminadas e com exemplares maciços. A granulação varia de argila a areia fina, sendo constituídas em essencial por grãos de quartzo, palhetas de micas e material síltico-argiloso.

A litologia apresenta como componente mineralógico: micas, carbonatos, quartzo, feldspato alterado e argilo-minerais, cimentados por óxido de ferro. Suas camadas mostram-se inclinadas, ora para sudeste, ora para noroeste, evidenciando seus dobramentos consequentes dos esforços tectônicos que dobraram o grupo Alto Paraguai (BARROS et al., 1982).

No médio curso da bacia hidrográfica do córrego Cachoeirinha registra-se a ocorrência das Formações: Sepotuba, Araras, Raizama (que já foram apresentadas e discutidas anteriormente) e a Formação Pantanal.

\section{Formação Pantanal}

Oliveira e Leonardos (1943) foram os primeiros geólogos a estudar e agrupar os sedimentos recentes e inconsolidados encontrados na Depressão do rio Paraguai, compostos por areias e argila, denominando-as de Formação Pantanal.

De acordo com Corrêa e Couto (1972) a Formação Pantanal é constituída de uma sequência argiloarenosa inconsolidada, estratificada horizontalmente, formada por uma alternância de argila cinza e areia média a fina, de cor branca, amarela e vermelha, com classificação regular a boa. Além do quartzo, as areias possuem conteúdo regular de caulim. Entremeados às camadas argilosas e arenosas, são localizados leitos laterizados de pequena espessura de areias e conglomerados finos.

Almeida (1964) diz que, os depósitos da Formação Pantanal são poucos espessos, com a composição areno-argilosos e síltico-argilosos, com granulometria predominantemente fina ou muito fina, ocorrendo também areias médias a conglomeráticos. Os grãos de quartzo são subarredondados e arredondados, as superfícies polidas com intercalações de níveis argilosos, tendo a fração cascalho, o resultado da movimentação ou dinâmica atual dos rios.

A presença dos fósseis de grandes mamíferos no pantanal comprova o início das formações dos depósitos arenosos que constituem o Pantanal Mato-Grossense a partir do Pleistoceno (GALETTI, 2004). 
Ao comparar a ocorrência dos canais fluviais deste trecho com alto curso, observa-se que houve redução na quantidade de afluentes do córrego Cachoeirinha. Esse fato está associado à geologia, às características do relevo, relativamente baixo e suavemente ondulado, cujas cotas altimétricas variam entre 120 e 300 metros e, consequentemente, a ausência de vales por onde poderiam concentrar o escoamento superficial.

No baixo curso da bacia do córrego Cachoeirinha ocorrem: Aluviões Atuais e a Formação Pantanal.

\section{Aluviões Atuais}

Os aluviões correspondem aos materiais inconsolidados que se encontram em deposição nos terraços e nas planícies fluviais no baixo curso da bacia hidrográfica do córrego Cachoeirinha próximo a confluência com o rio Paraguai.

A origem dos aluviões relaciona-se à dinâmica dos períodos de cheia do rio Paraguai, quando transbordam águas e sedimentos, depositando-os na planície de inundação. Nesse processo, misturam-se aos materiais transportados pelo córrego Cachoeirinha que também transborda durante os períodos de cheia nessa região, quando encontra um fluxo maior de água a jusante, provocando seu represamento.

Para Barros et al. (1982), o processo de deposição sedimentar pode ocorrer através dos depósitos de canal, barra, em pontal e transbordamento. A variação na composição do material depositado pode ser de areias, silte, argila e cascalho, reconhecendo-se que as camadas depositadas possuem pequena espessura, não atingindo 10 metros.

\section{CONSIDERAÇÕES FINAIS}

A influência da Geologia na bacia hidrográfica do córrego Cachoeirinha, em função do aquecimento das rochas, do solo e das camadas de ar sobre as serras e os morros, permiti a formação de duas unidades climáticas: Tropical de Altitude Mesotérmica Quente na Província Serrana com temperatura mínima anual de $17,1^{\circ} \mathrm{C}$ e máxima $31.8^{\circ} \mathrm{C}$. e Tropical Megatérmico Úmido na Depressão do alto Paraguai com mínima $19.7^{\circ} \mathrm{C}$ e as máximas $32.4^{\circ} \mathrm{C}$. o que propicia o aumento da temperatura e nos índices de precipitação, desempenhando um papel importantíssimo no comportamento hidrológico da bacia hidrográfica.

A bacia do córrego Cachoeirinha está sobre o embasamento de rochas da Formação do Grupo Alto Paraguai. No alto curso, as nascentes estão em uma área de arenito da formação Raizama. Nas sinclinais do alto e médio curso da bacia por onde escoa o canal principal, encontra-se a Formação Sepotuba. O relevo é movimentado em termos de formas e altitudes da Província Serrana. A rede de drenagem percorre as áreas de encostas e os vales, sendo influenciado pelo controle estrutural, apresentado fluxo turbulento com corredeiras e cachoeiras.

No médio curso aparece a rocha calcária dolomítica, apresentado feições de morros abaulados no topo, alinhados de forma paralela e, a Formação Pantanal constituída de uma estratificação horizontal argiloarenosa inconsolidada. 
No baixo curso, o córrego atravessa a Formação Pantanal e chega aos aluviões atuais com materiais inconsolidados que se encontram em processo de deposição associados diretamente com a dinâmica fluvial do rio Paraguai, onde o canal do córrego Cachoeirinha perde o controle estrutural e assume o padrão meandrante divagante, típico de planícies. Nesse contexto, considera-se que a Geologia presente na bacia influência nas características geoambientais e na dinâmica fluvial.

\section{REFERÊNCIAS}

ALMEIDA, F. F. M. Geologia do Centro-oeste Matogrossense. Boletim da Divisão de Geologia e Mineralogia. Rio de Janeiro, 1964. p.1-133.

ANDRADE, L. N. P. S.; SOUZA, C. A.; BINDANDI, N. M.; BINDANDI, S. C. Processos deposicionais na foz da baía Salobra confluência com o rio Paraguai em Cáceres-MT. In: SOUZA, C. A.. Bacia hidrográfica do rio Paraguai - MT: dinâmica das águas, uso, ocupação e degradação ambiental. São Carlos-SP: editora Cubo, 2012. p. 159 - 171.

BARROS, A. M.; SILVA, R. H.; CARDOSO, O. R. F. A.; FREIRE, F. A.; SOUZA JUNIOR, J. J.; RIVETTI, M.; LUZ, D. S.; PALMEIRA, R. C. B.; TASSINARI, C. C. G. Geologia. In: BRASIL. Ministério das Minas e Energia. Secretaria Geral. Projeto RADAMBRASIL. Folha SD. 21 - Cuiabá; Geologia, Geomorfologia, Pedologia, Vegetação e Uso potencial da terra. Rio de Janeiro, 1982. p. $25-192$.

BOTELHO, R. G. M. Planejamento ambiental em microbacia hidrográfica. In: GUERRA, A. J. T.; SILVA, A. S.; BOTELHO, R. G. M.. Erosão e conservação dos solos: conceitos, temas e aplicações. 6 ed. Rio de Janeiro: Bertrand Brasil, 2010. p. 269 -300 .

BRASIL. Ministério das Minas e Energia. Projeto RADAMBRASIL. Folha SD. 21 - Cuiabá: Geologia, Geomorfologia, Pedologia, Vegetação e Uso potencial da terra. Secretaria Geral. Rio de Janeiro, 1982. 544 p. BRASIL. Ministério do Exército. Diretoria de Serviço Geográfico. Região Centro Oeste do Brasil. Escala: 1:100.000. 1975.

BRIGANTE, J.; ESPÍNDOLA, E. L. G. A bacia hidrográfica: aspectos conceituais e caracterização geral da bacia do rio Mogi-Guaçu. In: BRIGANTE, J.; ESPÍNDOLA, E. L. G.. Limnologia Fluvial: um estudo no rio Mogi-Guaçu. São Carlos: RiMa, 2003. p. $01-13$.

CHRISTOFOLETTI, A. Geomorfologia. 2 ed. São Paulo. Editora Blucher, 1980.

CHRISTOFOLETTI, A. Modelagem de Sistemas Ambientais. 1 ed. São Paulo: Editora Blucher, 1999.

CORREA, J. A.; COUTO, E. A. Projeto aluviões diamantíferos de Mato Grosso. 2 vol. Relatório Final. Goiânia: DNPM/CPRM, 1972.

CUNHA, S. B. Geomorfologia Fluvial. In: GUERRA, A. J. T.; CUNHA, S. B.. Geomorfologia: uma atualização de bases e conceitos. 8 ed. Rio de Janeiro: Bertrand Brasil, 2008. p. 211 -234 .
GALETTI, M. Parques do Pleistoceno: recriando o Cerrado e o Pantanal com a megafauna. Natureza \& Conservação, v.2, n.1, 2004.

GUERRA, A. T.; GUERRA, A. J. T. G. Novo dicionário geológico-geomorfológico. 6 ed. Rio de Janeiro: Bertrand Brasil, 2008.

KARMANN, I. Água: ciclo e ação geológica. In: TEIXEIRA, W.; FAIRCHILD, T. R.; TOLEDO, M. C. M.; TAIOLI, F.. Decifrando a Terra. 2 ed. São Paulo: Companhia Editora Nacional, 2009. p. $186-209$.

LUZ, J. S.; OLIVEIRA, A. M.; LEMOS, D. B.; ARGOLO, J. L.; SOUZA, N. B.; ABREU FILHO, W. Projeto Província Serrana. 8 vol. Relatório Final. Relatório do Arquivo Técnico (DGM, 2750) v.1. Goiânia: DNPM/CPRM, 1978.

NUNES, B. A.; RIBEIRO, M. I. C.; ALMEIDA, V. J.; NATALI FILHO, T. Manual Técnico de Geomorfologia. Rio de Janeiro: IBGE, Departamento de Recursos Naturais e Estudos Ambientais, 1994.

OLIVEIRA A, I.; LEONARDOS, O. H. Geologia do Brasil. 2. ed. Rio de Janeiro: Serviço de Informação Agrícola, 1943.

POPP, J. H. Geologia Geral. 6 ed. Rio de Janeiro: LTC, 2010.

RITELA, A.; SOUZA, C.A. Caracterização da bacia hidrográfica do rio Aguapeí - MT, como subsídio para uso e conservação. Revista Eletrônica da Associação dos Geógrafos Brasileiros - Seção Três Lagoas, Três Lagoas/ MS. n 7, ano 5, maio de 2008.

ROSS, J. L. S.. Estudo e cartografia geomorfológica da Província Serrana de Mato Grosso. Tese (Doutorado) Universidade de São Paulo, 1987.

ROSS, J. L. S. Geomorfologia ambiental. In: CUNHA, S. B.; GUERRA, A. J. T.. Geomorfologia do Brasil. 5 ed. Rio de Janeiro: Bertrand Brasil, 2009. p. 351 - 388.

SILVEIRA, A. L. L. Ciclo hidrológico e bacia hidrográfica. In: TUCCI, C.E.M. (Org.) Hidrologia: ciência e aplicação. São Paulo: ed. USP, 1993. p. 35 - 51.

SOARES, J. C. O. Estudo de nascentes: subsídio a políticas de gestão da sub-bacia hidrográfica do córrego Caeté no sudoeste do Estado de Mato Grosso. Dissertação (Mestrado em Ciências Ambientais) Universidade do Estado de Mato Grosso, Cáceres, 2009.

SOUZA, C. A. Bacia hidrográfica do córrego Piraputanga-MT: avaliação da dinâmica atual. Dissertação (Mestrado em 
Geografia). Universidade Federal do Rio de Janeiro, Rio de Janeiro, 1998.

SOUZA, C. A. Bacia hidrográfica do córrego Piraputanga-MT: avaliação da dinâmica atual. Dissertação (Mestrado em Geografia). Universidade Federal do Rio de Janeiro. Rio de Janeiro, 1998.

SOUZA, M. A.; TOSTA, R. M. S. Estudo preliminar quantitativo das características da rede de drenagem da subbacia do córrego Macaúba/MS. In: JORGE, A. C.; FERREIRA, Z. S. Eco-pantanal Matogrossense: Gestão Ambiental. CáceresMT: ed. UNEMAT, 2010. p. $83-103$.
SUGUIO, K. Geologia do quaternário e mudanças ambientais. São Paulo: Oficina de textos, 2010.

SUGUIO, K.; BIGARELLA, J. J. Ambiente fluvial. 2 ed. Florianópolis: edUFSC, 1990.

VALENTE, O.; GOMES, M. A. Conservação de nascentes: hidrologia e manejo de bacias hidrográficas de cabeceiras. Viçosa-MG: Aprenda Fácil, 2005.

WILSON, J. L. Carbonate facies in geologic in history. New York, Springer-Verlag, 1975. p. 26 - 27.

A CBPC - Companhia Brasileira de Produção Científica (CNPJ: 11.221.422/0001-03) detém os direitos materiais desta publicação. Os direitos referem-se à publicação do trabalho em qualquer parte do mundo, incluindo os direitos às renovações, expansões e disseminações da contribuição, bem como outros direitos subsidiários. Todos os trabalhos publicados eletronicamente poderão posteriormente ser publicados em coletâneas impressas sob coordenação da Sustenere Publishing, da Companhia Brasileira de Produção Científica e seus parceiros autorizados. Os (as) autores (as) preservam os direitos autorais, mas não têm permissão para a publicação da contribuição em outro meio, impresso ou digital, em português ou em tradução. 